\title{
Practical fire design of partially encased composite steel-concrete columns according to Eurocode 4
}

\author{
Sadaoui Arezki ${ }^{1}$, Illouli Said ${ }^{1}$ \\ ${ }^{1}$ University Mouloud Mammeri of Tizi-ouzou, Department of civil engineering, Tizi-ouzou, Algeria
}

\begin{abstract}
A practical method based on Campus-Massonet criteria which is developed initially to steel structures with combined compression and bending is adapted for the calculation of the buckling resistance of eccentrically loaded columns. The latter at room temperature or in fire situation is expressed by a simple formula as a function of an equivalent buckling coefficient taking into account the amount the eccentricity of the compressive applied load. The method proposed combines accuracy, efficiency and convenience obviating the need of M-N interaction diagrams and long iteration process. Otherwise, the estimation of the fire resistance for a given loading is made on the assumption based on the linearity with the level applied compressive load. It was found that the fire resistance of a column subjected to an eccentric load decreases gradually with the increase in the load level $(\eta)$, the slenderness ratio $(\lambda)$ or the amount of the eccentricity. For a fire resistance of one hour, time enough to evacuate the building of all its occupants, it recommended to use $\eta \leq 0.5$ and $\lambda \leq 45$. The range of values of reinforcement cover $(u)$ suggested by Eurocode 4 leads to a better fire resistance except for $\mathrm{u}=60 \mathrm{~mm}$ where there is a decline of the about $10 \%$.
\end{abstract}

\section{Introduction}

The theoretical evaluation of the fire resistance of partially encased composite steel-concrete columns is very complex, and is not practical for everyday design. To this end, the Eurocode 4 in its part 1-2 [01] proposes two methods to determine the fire resistance of composites columns subject to a standard ISO fire. The first uses tabulated values previously established for the most common cross-sections based on experimental and empirical results. Often of a quick and easy application, its results are generally very conservative as it predicts very high values for the required reinforcement. Yet, this method is still useful, at least in the preliminary design stages, where it can be used to choose between a composite steel-concrete structure and an equivalent steel structure with adequate fire protection.

The second method which had been at the origin developed by Jungbluth [02], is based on simplified analytical formulas for individual structural elements. Its principle is to calculate the ultimate load carrying capacity of the element by dividing the section into different zones. The material properties for each zone are modified using reduction factors, which depend on the average temperature in the zone. These temperatures are determined by considering the section to be exposed to an ISO fire for the required fire resistance period. For partially encased profiles, this method is detailed in EC4 1-2 Appendix G. The apparent simplicity of this method is indeed relatively superficial because of more tasks which are involved by handle calculation when especially the compression load applied to the column is eccentric. In fact, The Eurocode 4 unfactored eccentric load strength was based on the cross-section and column axial load bending moment strength interaction diagrams, which needs in the first step to be calculated. An approximate five-points M-N diagram is usually considered for bending applied about the minor axis of the partially encased steel-section. In the second step, the approximated interaction curve is used in the design procedure using a step-by-step to determine finally by doing some iterations the ultimate eccentric resistance for the whole column.

The aim of the present investigation is to present an efficient simple and practical method for the calculation of the buckling load resistance of an encased composite steel-concrete columns subjected to eccentric loading.

\section{Principles of fire design}

The fire resistance of a structural element is defined as the time during which the element continues to fulfil its load bearing role in spite of the action of the fire. There exist three different ways to establish the requirements for fire resistance of a structural element $[03,04,05]$. They are illustrated in Figure 1 for a standard ISO 834 standard fire [6], whose temperatures are constantly increasing. The fire resistance can be obtained: i) in terms of duration, where the resistance time, $t_{f i, d}$, must be 
greater than the time required $t_{f i, r e q}$; ii) either in terms of resistance, where the load carrying capacity $R_{f i, d}$ must be greater than the effect of the imposed loading $E_{f i, d}$ at a given time $t=t_{f i}$; iii) or finally in terms of temperature, where the temperature of $\theta_{d}$ must be less than the critical temperature $\theta_{c r, d}$ at the specified time $t_{\text {fi,req. }}$
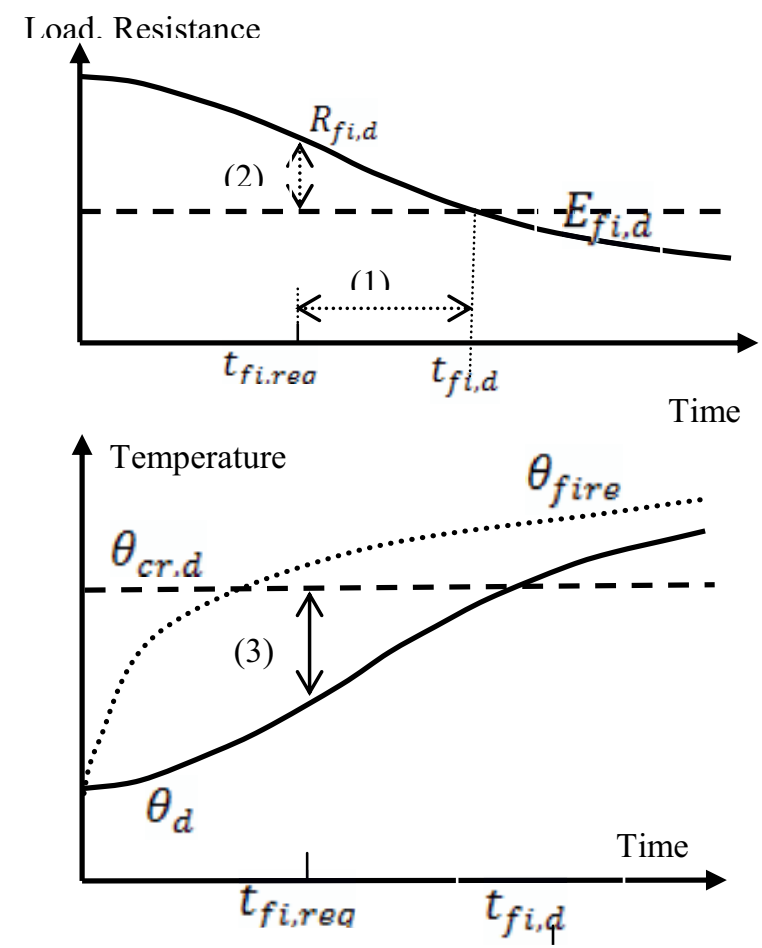

Fig.1: Schematic representation of fire design strategies

However, whatever method is chosen, the calculations should be carried out at the ultimate limit state. In practice, the determination of the fire resistance in terms of temperature can only be achieved if the element's temperature is uniform as in some steel elements, or if the ruin is conditioned by the behaviour of an element that can be characterized by its temperature; for example a reinforced concrete slab whose behaviour is conditioned by the temperature of the lower reinforcement. This check in terms of temperature is obviously not possible if the temperature field is not uniform, as is usually the case in composite steel and concrete elements.

\section{Determination of the fire resistance of partially encased composite steel- concrete columns}

The fire resistance of partially encased composite steel-concrete columns can be obtained using the simplified method given in Appendix G of EC4 1-2. The designer should check that the axial load in service, increased by using the appropriate load factors, is less than the resistance of the composite column. The procedure is essentially based on three main steps:

1- Determination of the plastic resistance to axial compression

2- Calculation of the buckling resistance without eccentricity

3- Performing the calculation with consideration of the eccentricity

\subsection{Determination of the plastic resistance}

The design value of the plastic resistance to axial compression of the column section in the fire situation symbolised by the lower subscript $\left(\mathrm{f}_{\mathrm{i}}\right)$, is obtained as:

$N_{f, p l, R d}=A_{a} \times f_{a y} / \gamma_{M, f, a}+A_{c} \times 0.85 \times f_{c k} / \gamma_{M, f, c}+A_{s} \times f_{s k} / \gamma_{M, f, s}$

where: $A_{a}$ is the area of the reinforcing bars and $\mathrm{f}_{\mathrm{ay}}$ their yield strength, $A_{c}$ is the area of the concrete and $f_{c k}$ its compressive characteristic strength, As is the area of the profile, and $\mathrm{f}_{\mathrm{sk}}$ its yield strength and, $\gamma_{M, f i, a}$, $\gamma_{M, f i, c}, \quad \gamma_{M, f i, s}$ are safety coefficients in the fire situation case.

It is evaluated by dividing the cross section into four parts as shown in Fig. 2; namely: the flanges of the profile, the web of the profile, the reinforcing bars, and the concrete. Depending on the required fire resistance (R30, R60, R90 or R120), a reduced characteristic strength, a reduced elastic modulus, and a reduced cross section area is determined for each part depending on its average temperature which corresponds to time $t$ of fire exposure Note that a linear interpolation between the values is permittı

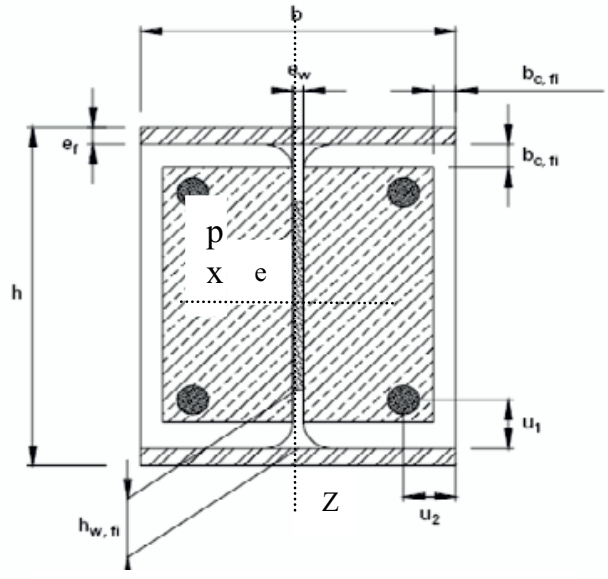

Fig. 2: Reduced fire cross- section

\subsection{Concentric loaded column}

The buckling resistance or the resistance in axial compression of the column is a function of the plastic resistance and the eccentricity of the applied load (P). In case of a concentric loading $(\mathrm{e}=0)$, it is given as: 
$N_{f_{i}, R d}=\chi_{0} N_{f_{i}, p l, R d}$

where $\chi_{0}$ is a coefficient representing the slenderness of the column around the faible axis in reference to the eccentricity $\mathrm{e}=0$, and is a function of the dimensionless slenderness ratio, $\bar{\lambda}_{\theta}$, which in turn is obtained by:

$\bar{\lambda}_{\theta}=\sqrt{N_{f_{i}, p l, R} / N_{f_{i}, c r}}$

where $N_{f_{i}, p l, R}$ represents the value of $N_{f_{i}, p l, R d}$ when the safety factors $\gamma_{M, f i, a}, \gamma_{M, f i, c}$ and $\gamma_{M, f i, s}$ are taken equal to unity. The slenderness coefficient $\chi_{0}$ of the column, which is calculated around the weak axis (z), can be obtained from the buckling curve c , figure 6.4, clause 6.3.1.2 of EC3-1-1 [7] or from the following equation:

$$
\chi_{0}=\frac{1}{\Phi+\sqrt{\Phi^{2}-\bar{\lambda}^{2}}}
$$

where $\Phi=0.5\left[1+\alpha(\bar{\lambda}-0.2)+\bar{\lambda}^{2}\right\rfloor$ with $\alpha$ is a perfection factor corresponding to the appropriate buckling curve which is taken equal to 0.49 for the buckling curve c. The term $N_{f_{i}, c r}$ represents the Euler buckling load or elastic critical load in a fire situation, and is given as:

$N_{f_{i}, \text { cr }}=\Pi^{2}(E I)_{f_{i}, \text { eff }} / \ell_{\theta}^{2}$

where $l_{\theta}$ is the buckling length of the column in a situation of fire, and $(E I)_{f_{i}, \text { eff }}=\sum_{i=1}^{4}(E I)_{i}$ is the sum of the weighted stiffness's of the different parts depending on the values of their respective elastic modulus and the reduced second moment of area with respect to the weak axis which is defined in the relation 4-14, clause 4.3.5.1-5 of EN EC4 1-2.

\subsection{Eccentric loaded column}

For a column submitted to a load with an eccentricity e, the design buckling load can be obtained from the formula as suggested by EN EC4 1-2:

$$
N_{f_{i}, R d, e}=N_{f i, R d} \cdot \frac{N_{R d, e}}{N_{R d}}
$$

where $N_{R d}$ and $N_{R d, e}$ represent both for normal temperatures design respectively the axial buckling load without eccentricity, and the buckling load in case of the consideration of an eccentricity (e) of the applied compression load. Accordingly to EC4, the calculation of $\mathrm{N}_{\mathrm{Rd}, \mathrm{e}}$ is performed through an iteration process where at first, the load carrying resistance of the cross-section is calculated. A M-N interaction curve of four-point polygon is calculated on the basis of the equilibrium of the cross-section between the internal and external forces in function of the neutral axis position. The five-point polygon were determined using the assumptions that the structural steel section and reinforcing steel bars were fully plasticized in tension or compression on adjacent sides of the neutral axis with stress ordinates equal to their yield strengths and a rectangular compressive stress block with a stress ordinate of $0.85 \mathrm{f}_{\mathrm{ck}}$ was distributed uniformly over the concrete are between the compression face and the neutral axis. The interaction curve like the one illustrated in fig. 3 with the known plastic design resistance load $\mathrm{N}_{\mathrm{pl}, \mathrm{Rd}}$ and the ultimate bending resistance $\mathrm{M}_{\mathrm{pl}, \mathrm{Rd}}$, is used in the design procedure using a step-bystep procedure as follows:

1- Knowing the resistance in axial compression $\mathrm{N}_{\mathrm{Rd}}$ and $\chi=\mathrm{N}_{\mathrm{Rd}} / \mathrm{N}_{\mathrm{pl}, \mathrm{Rd}}$ the points $\mathrm{A}$ and $\mathrm{B}$ are defined, $v_{\chi}$ being the corresponding bending resistance of the cross-section.

2- The design load $\mathrm{N}_{\mathrm{d}}$ gives the factor $\chi_{d}=N_{d} / N_{p l, R d}$ and the points $\mathrm{C}$ and $\mathrm{D}, v_{d}$ being the corresponding bending resistance of the cross-section which the length $v$ is determined by: $v=v_{d}-v_{\chi} \cdot \chi_{d} / \chi$

3- The design moment is calculated with second order theory and defined as: $M_{d}=N_{d} \cdot e . k(n)$ where $\mathrm{e}$ is eccentricity and $k(n)$ is an amplification factor which is depending on the elastic critical load of the column $N_{c r}$ and given by: $\quad k(n)=(1+0.25 n) /(1-n)$ with $n=N_{d} / N_{c r}$.

4- The column has sufficient resistance if $M_{d} \leq 0.9 v M_{p l, R d}$. If this condition is not fulfilled a reduction of the designing load or a reduction of the eccentricity is necessary or a greater column section must be chosen. If the difference between $0.9 v M_{p l, R d}$ and $\mathrm{M}_{\mathrm{d}}$ is important one may increase the design load or the design eccentricity. By doing some iterations, the ultimate eccentric load for the column can finally be determined where in this case $\mathrm{N}_{\mathrm{Rd}, \mathrm{e}}=\mathrm{N}_{\mathrm{d}}$.

As can be seen, when the eccentricity of loading is taken into account, the method of EC 4 is somewhat relatively complex for an everyday practise and it needs necessarily the computer programming. A practical approach based on Campus Massonnet formula [8] elaborated initially to steel structures is adapted where the buckling resistance of a composite steel-concrete column eccentrically loaded can be solely formulated as:

$$
N_{f_{i}, R d, e}=\chi_{e} \cdot N_{f i, R d}
$$


where $\chi_{e}$ is an equivalent correction buckling coefficient depending on the eccentricity, and given as:

$$
\chi_{e}=\frac{\chi_{0}(\bar{\lambda})}{1+\frac{k_{1} \cdot e}{h\left(\frac{1}{\chi_{0}(\bar{\lambda})}-0.3 \bar{\lambda}^{2}\right)}}
$$

with $\mathrm{k}_{1}=4$. However, the application point of the eccentric load should remain inside the composite crosssection of the column namely does not exceed $h / 2$ or $b / 2$ accordingly to the strong or weak axis which is considered in the calculation.

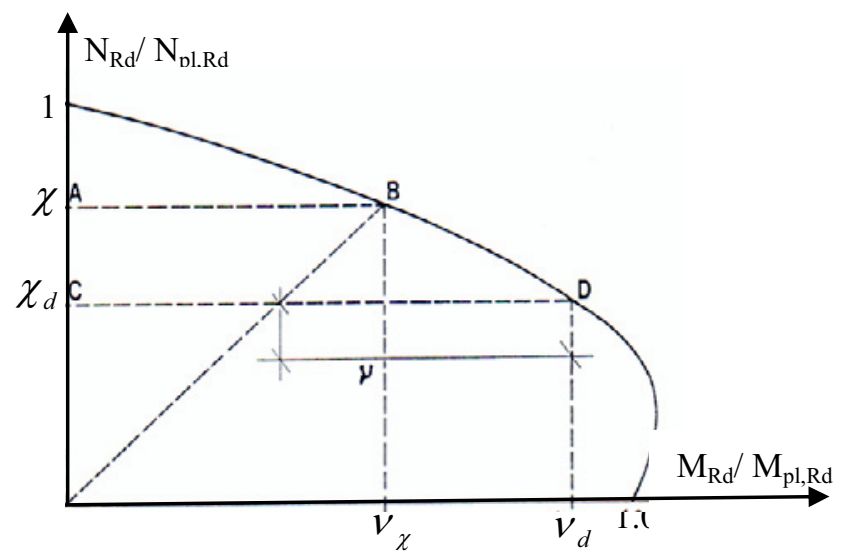

Fig. 3 Interaction N-M curve for uniaxial bending

\section{Worked example}

Figure 4 shows an eccentric pin-ended column with a partially encased composite cross-section made of HD $400 \times 400 \times 187$ steel profile. It is an interior column on the ground floor of a five storeys office building. The column is heated on all four sides and subjected to a standard fire type ISO834. The storey height is 3.75 meters and the applied load is assumed to act at $30 \mathrm{~mm}$ from the weak axis $(\mathrm{z})$. The geometrical data and material properties relevant to the column are summarised in Table 1 . The yield strength of the steel profile is reduced to $f_{a y}=285 \mathrm{~N} / \mathrm{mm}^{2} \quad$ because the flange thickness exceeds $16 \mathrm{~mm}$ [9], and the moments of inertia are calculated relative to the minor axis $(\mathrm{z})$.

In the following, we propose to check whether first the stability of the column is justified at room temperature, second the current design requirements satisfies for a fire resistance of R60, and third to determine the fire resistance for an applied given load of $2110 \mathrm{kN}$. The load path of the upper floors and roof level is supposed to give the respective values to ground floor: weight of structure $(1400 \mathrm{kN})$, dead loads $(360 \mathrm{kN})$ and live loads $(700 \mathrm{kN})$. The following load combinations from Eurocode 1 [10] are used to determine the design value of axial applied load:
- at room temperature conditions: $N_{s d}=(1400+$ $360) \times 1,35+700 \times 1,5=3426 \mathrm{kN}$

- at fire conditions $($ avec $\psi 1=0,5): N_{S d, f i}=(1400+$ $360) \times 1,00+700 \times 0,5=2110 \mathrm{kN}$.

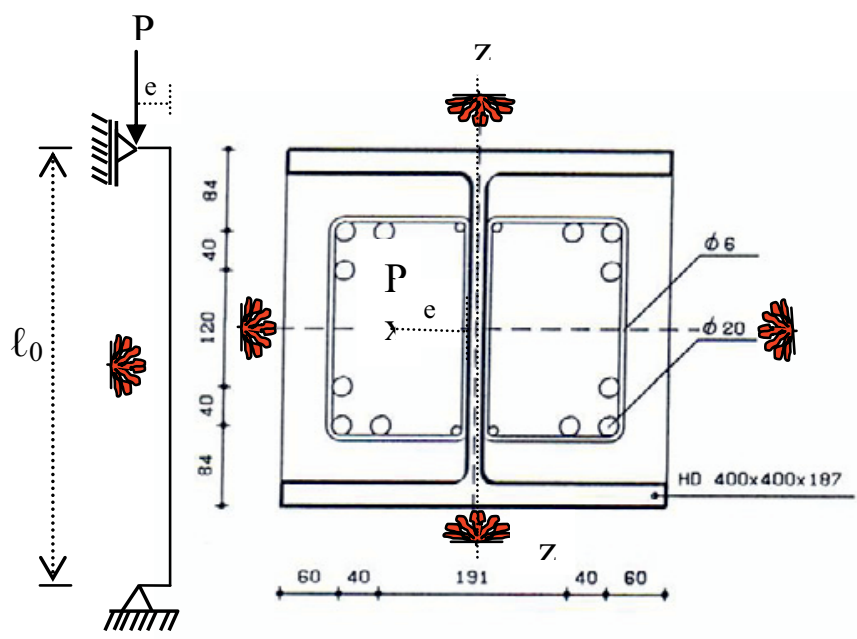

Fig. 4: Geometric details of an eccentric loaded column

Table 1: Geometrical and material properties

\begin{tabular}{|l|l|l|}
\hline \multicolumn{1}{|c|}{ Steel profile } & \multicolumn{1}{c|}{ Concrete } & \multicolumn{1}{c|}{ reinforcement } \\
\hline HD400x400x187 & Concrete: C50 & Grade steel : S500 \\
Steel: $\mathrm{S} 295$ & $\mathrm{f}_{\mathrm{ck}}=50 \mathrm{MPa}$ & Diameter: $12 \varnothing 20$ \\
$\mathrm{~h}=368.0 \mathrm{~mm}$ & $\mathrm{~A}_{\mathrm{c}}=1164 \mathrm{~cm}^{2}$ & $\mathrm{~A}_{\mathrm{s}}=37.68 \mathrm{~cm}^{2}$ \\
$\mathrm{~b}=391.0 \mathrm{~mm}$ & $\mathrm{E}_{\mathrm{cd}}=24750 \mathrm{MPa}$ & $\mathrm{f}_{\mathrm{sk}}=500 \mathrm{MPa}$ \\
$\mathrm{e}_{\mathrm{w}}=15.0 \mathrm{~mm}$ & $\mathrm{I}_{\mathrm{cz}}=153625.5$ & $\mathrm{E}_{\mathrm{sk}}=200 \mathrm{GPa}$ \\
$\mathrm{e}_{\mathrm{f}}=24.0 \mathrm{~mm}$ & $\mathrm{~cm}^{4}$ & $\mathrm{I}_{\mathrm{sz}}=5767 \mathrm{~cm}^{4}$ \\
$\mathrm{~A}_{\mathrm{a}}=23760 \mathrm{~mm}^{2}$ & & $\mathrm{u}=\sqrt{u_{1} \cdot u_{2}}=60$ \\
$\mathrm{f}_{\mathrm{ay}}=295 \mathrm{MPa}$ & & $\mathrm{mm}$ \\
$\mathrm{E}_{\mathrm{a}}=205 \mathrm{GPa}$ & & \\
$\mathrm{I}_{\mathrm{az}}=23922 \mathrm{~cm}^{4}$ & & \\
\hline
\end{tabular}

\subsection{Justification of the stability at room temperature}

Plastic resistance to axial compression:

$$
\begin{aligned}
N_{p l, R d}= & A_{a} \times f_{a y} / \gamma_{a}+A_{c} \times 0.85 \times f_{c k} / \gamma_{c}+A_{s} \times f_{s k} / \gamma_{s} \\
= & (23760 \times 285 / 1.10+116360 \times 0.85 \times 50 / 1.50+ \\
& 3768 \times 500 / 1.15) / 1000=11091.1 \mathrm{kN}
\end{aligned}
$$

and, when all the safety coefficients are taken to 1.00 , it follows from the previous formula:

$$
\begin{aligned}
N_{p l, R}= & A_{a} \times f_{a y}+A_{c} \times 0.85 \times f_{c k}+A_{s} \times f_{s k} \\
= & (23760 \times 285+116360 \times 0.85 \times 50+ \\
& 3768 \times 500) / 1000=13600.9 \mathrm{kN}
\end{aligned}
$$

Part contribution of steel profile: $23760 \times 285 / 1.10=6156$ $\mathrm{kN}$, relatively to the plastic total resistance: $\delta=6156 / 11091.1=0.555$. The condition $0.2 \prec \delta \prec 0.9$ is satisfied.

Elastic critical load $\left(\ell=1.0 \times \ell_{0}=3750 \mathrm{~mm}\right.$ : for room temperature):

$N_{c r}=\pi^{2}\left(E_{a} I_{a}+E_{s} I_{s}+0.8 E_{c d} I_{c}\right) / \ell^{2}$ 
$=\frac{\pi^{2} \times 10^{4}}{3750^{2}}(205000 \times 23922+200000 \times 5767+0.8 \times 24750 \times 153625.5) / 10$

$=63796.9 \mathrm{kN}$.

Relative slenderness:

$\bar{\lambda}=\sqrt{N_{p l, R} / N_{c r}}=\sqrt{13600.9 / 63796.9}=$

0.4617 . The condition $\bar{\lambda} \prec 2.0$ is satisfied.

Buckling curve c from EC3 1-1 [7] or from equation (4) gives the reduction coefficient in case of concentric loading $\chi_{0}=0.8638$.

Reduction coefficient buckling with the eccentricity $\mathrm{e}=$ $98 \mathrm{~mm}$ around the axis $\mathrm{z}$ :

$$
\begin{aligned}
& \chi_{e}=\frac{\chi_{0}(\bar{\lambda})}{1+\frac{4 . e}{b\left(\frac{1}{\chi_{0}(\bar{\lambda})}-0.3 \bar{\lambda}^{2}\right)}} \\
& =\frac{0.8638}{1+\frac{4 \times 98}{391\left(\frac{1}{0.8638}-0.3 \times 0.4617^{2}\right)}}=0.4507
\end{aligned}
$$

The buckling resistance load of the whole column is finally: $N_{R d, e}=\chi_{e} N_{p l, R d}=0.4507 \times 11091.1=4998.8$ $\mathrm{kN}$ where when the eccentricity is neglected $\mathrm{N}_{\mathrm{Rd}}=$ $0.8638 \times 11090.1=9580.5 \mathrm{kN}$. Noting that the calculation with Eurocode 4 procedure in term of comparison gives for $\mathrm{N}_{\mathrm{Rd}, \mathrm{e}}$ a value of $5100 \mathrm{kN}$ which is less than $2 \%$, which the equivalent factor of 'proportionality' reduction is: $r_{e}=N_{R d, e} / N_{R d}=0.5323$.

$\mathrm{N}_{\mathrm{sd}}=3426<4998.8 \mathrm{kN}$. The stability of the column at room temperature is widely satisfied.

\subsection{Calculation of the load carrying capacity for $\mathrm{R} 60$ ( $\mathrm{t}=60 \mathrm{~min}$ )}

As a preamble, it is necessary to check if the cross section is well within the limits of applicability of the method for the class of fire resistance R60. These limits are defined in the paragraph G-8, EN EC4 1-2, and are all well within the limits.

\subsubsection{Contribution of the flanges}

The average temperature in the flanges is calculated by: $\theta_{f, t}=\theta_{0, t}+k_{t}\left(A_{m} / V\right)$ where $\mathrm{t}=60 \mathrm{~min}$ represents the duration of the fire.

The massivity factor is obtained as:

$$
\frac{A_{m}}{V}=\frac{2(h+b)}{h b}=\frac{2 \times(0.391+0.368)}{0.391 \times 0.368}=10.550 \mathrm{~m}^{-1}
$$

For R60, Table G.1 gives $\theta_{0, t}=680^{\circ} \mathrm{C}$ and $k_{t}=9.55 \mathrm{~m}^{\circ} \mathrm{C}$. It follows therefore that:

$\theta_{f, t}=680+9.55 \times 10.550=780.8{ }^{\circ} \mathrm{C}$

From table 3.2 of EN EC4-1-2, and interpolating for $780.8^{\circ} \mathrm{C}$, we obtain: $\mathrm{k}_{\max , \theta}=0.1330$ and $\mathrm{k}_{\mathrm{E}, \theta}=0.0977$ The reduced yield strength and the reduced elastic modulus are: $f_{a, \max , f, t}=f_{a y, f, 20^{\circ} \mathrm{C}} \cdot k_{\max , \theta}=285 \times 0.1330=$ $37.91 \mathrm{~N} / \mathrm{mm}^{2} \mathrm{E}_{a, f t}=E_{a, f 20^{\circ} \mathrm{C}} \cdot k_{E, \theta}=205000 \mathrm{x} 0.0977$ $=20028.5 \mathrm{~N} / \mathrm{mm}^{2}$. The plastic strength of the two flanges is: $N_{f i, p l . R d, f}=2$ (b.e $\left.f \cdot f_{a} \max , f, t\right) / \gamma_{M,} f i, a=$ $2 \times(391 \times 24.0 \times 37.91) / 1.0=711494.9 N$. The effective flexural stiffness with respect to the weak axis in fire is:

$(E . I)_{f i, f, z}=\mathrm{E}_{a, f, t} \cdot\left(e_{f} \frac{b^{3}}{6}\right)=20028.5 \times 24.0 \times 391^{2} / 6=$ $4.8 \times 10^{12}$ N.mm ${ }^{2}$

\subsubsection{Contribution of the web}

From table G.2, $\mathrm{H}_{\mathrm{t}}=770 \mathrm{~mm}$ for $\mathrm{R} 60$.

The height of the web to be neglected is therefore, which is beginning at the inner edge of the flange:

$$
\begin{aligned}
h_{w, f_{i}} & =0.5\left(h-2 e_{f}\right)\left(1-\sqrt{1-0.16\left(H_{t} / h\right)}\right. \\
& =0.5 \times(368-2 \times 24.0) \times\left(1-\sqrt{1-0.16 \times \frac{770}{368}}\right. \\
& =29.50 \mathrm{~mm}
\end{aligned}
$$

The reduced characteristic strength is:

$$
\begin{aligned}
& f_{a \max , w, t}=f_{a y, w, 20^{\circ} \mathrm{C}} \sqrt{1-0.16\left(H_{t} / h\right)} \\
& =285 \times \sqrt{1-0.16 \times \frac{770}{368}}=232.4 \mathrm{MPa}
\end{aligned}
$$

The plastic strength of the web is: $N_{f i, p l, R_{d}, w}=e_{w}\left(h-2 e_{f}-2 h_{w, f_{i}}\right) \cdot f_{a \max , w, t} / \gamma_{M, f_{i}, a}$ $=15 \times(368-2 \times 24.0-2 \times 29.50) \times 232.4 / 1.0=909846.0 \mathrm{~N}$ The effective flexural stiffness is:

$$
\begin{aligned}
(E I)_{f_{i}, w, z} & =E_{a, w, 20^{\circ} C}\left(h-2 e_{f}-2 h_{w, f_{i}}\right) \cdot e_{w}^{3} / 12 \\
& =205000 \times(368-2 \times 24.0-2 \times 29.5) \times 15^{3} / 12 \\
& =0.15048 \times 10^{11} \mathrm{~N} \cdot \mathrm{mm}^{2}
\end{aligned}
$$

\subsubsection{Contribution of the reinforcement}

The reduction factor for the yield strength of the reinforcement is obtained from Table G-5:

$u=\sqrt{u_{1} \cdot u_{2}}=\sqrt{60 \times 60}=60 \mathrm{~mm}$ and $\mathrm{k}_{\mathrm{y}, \mathrm{t}}=1.0$ for R60. The Reduction factor for the elastic modulus of the reinforcement is obtained from Table G-6:

$\mathrm{K}_{\mathrm{E}, \mathrm{t}}=0.763$ for $\mathrm{R} 60$

The plastic strength of the reinforcement is:

$$
\begin{aligned}
N_{f i, p l, R_{d}, s} & =A_{s} \cdot k_{y, t} f_{s y, 20^{\circ} C} / \gamma_{M, f_{i}, s} \\
& =3768 \times 1.0 \times 500 / 1.00=1884000 \mathrm{~N}
\end{aligned}
$$

The second moment of area of the bars with respect to the axis $\mathrm{z}$; the centroid of outer and inner bar layers are located respectively at a distance of $135.5 \mathrm{~mm}$ and 95.5 $\mathrm{mm}$ from the median axis of the web: 
$\mathrm{I}_{\mathrm{sz}}=12 \times \pi \times 10^{4} / 4+\pi \times 10^{2} \times\left(8 \times 135.5^{2}+4 \times 95.5^{2}\right)=$ $57670182 \mathrm{~mm}^{4}$. The effective flexural stiffness with respect to the weak axis is hence obtained as:

$$
\begin{aligned}
& (E I)_{f_{i}, s, z}=k_{E, t} \cdot E_{s, 20^{\circ} \mathrm{C}} \cdot I_{s, z}= \\
& 0.763 \times 200000 \times 57670182=8.800 \times 10^{12} \mathrm{~N} \cdot \mathrm{mm}^{2}
\end{aligned}
$$

\subsubsection{Contribution of the concrete}

The thickness $b_{c, f i}$ of concrete neglected in the calculation is from Table G-3: $b_{c, f i}=15 \mathrm{~mm}$

The average temperature of the concrete for $\quad \mathrm{A}_{\mathrm{m}} / \mathrm{V}=$ $10.550 \mathrm{~m}^{-1}$ is obtained from Table G-4 as:

$\theta_{c, t}=312.92{ }^{\circ} \mathrm{C}$ which, through interpolation in the

Table 3.3, yields $k_{c, \theta}=0.837$ and $\varepsilon_{c u, \theta}=7.388 \times 10^{-3}$.

The secant elastic modulus of the concrete is hence:

$E_{c, \mathrm{sec}, c}=f_{c, \theta} \varepsilon_{c u, \theta}=f_{c, 20^{\circ} \mathrm{C}} \cdot k_{c, \theta} / \varepsilon_{c u, \theta}=$

$50 \times 0.837 / 7.388 \times 10^{-3}=5664.6 \mathrm{~N} / \mathrm{mm}^{2}$

The plastic strength to axial compression is obtained with

$\gamma_{M, f i, c}=1.30$ as:

$N_{f f, p l, R_{d}, c}=0.86\left[\left(h-2 e_{f}-2 b_{c, f_{i}}\right)\left(b-e_{w}-2 b_{c, f_{i}}\right)-A_{s}\right] f_{c, \theta} / \gamma_{M, f_{i, c}}$

$=0.86[(368-2 \times 24.0-2 \times 15.0)(391-15-2 \times 15.0)-3768]$

$\times 50 \times 0.837) / 1.30=2673633.0 \mathrm{~N}$

The effective flexural stiffness with respect to the weak axis

$(E I)_{f_{i}, c, z}=E_{c, \mathrm{sec}, \theta}\left\lfloor\left\{\left(h-2 e_{f}-2 b_{c, f_{i}}\right)\left(\left(b-2 b_{c, f_{i}}\right)^{3}-e_{w}^{3}\right) / 12\right\}-I_{s, z}\right\rfloor$ $=5664.6 \times\left[\left\{(368-2 \times 24.0-2 \times 15.0)\left((391-2 \times 15.0)^{3}-15^{3}\right) / 12\right\}-57670182\right]$ $=6.113 \times 10^{12} \mathrm{~N} \cdot \mathrm{mm}^{2}$.

\subsubsection{Buckling axial load at an elevated temperature (R60)}

The calculation follows generally the same procedure as for the calculation at room temperature.

The total Plastic strength in axial compression is:

$$
\begin{aligned}
N_{f i, p l, R_{d}}= & N_{f i, p l, R_{d}, f}+N_{f i, p l, R_{d}, w}+N_{f i, p l, R_{d}, c}+N_{f i, p l, R_{d}, s} \\
= & 711494.9+909846.0+1884000.0 \\
& +2693511.1=6198852.0 \mathrm{~N}
\end{aligned}
$$

The effective flexural stiffness of the column is obtained as:

$(E I)_{f_{i}, e f f, z}=\varphi_{f, \theta}(E I)_{f_{i}, f, z}+\varphi_{w, \theta}(E I)_{f_{i}, w, z}+\varphi_{c, \theta}(E I)_{f_{i}, c, z}+\varphi_{s, \theta}(E I)_{f_{i}, s, z}$ where from Table G-7: $\varphi_{f, \theta}=0.9 ; \varphi_{w, \theta}=1.0 ; \varphi_{s, \theta}=$

0.9 and $\varphi_{c, \theta}=0.8$. It gives:

$$
\begin{aligned}
(E I)_{f i \text { eff. }}= & 0.9 \times 4.8 \times 10^{12}+1.0 \times 0.02 \times 10^{12}+0.9 \times 8.8 \times 10^{12} \\
& +0.8 \times 6.1 \times 10^{12}=17.14 \times 10^{12} \text { N.mm }
\end{aligned}
$$

The elastic critical buckling load is:

$$
\begin{aligned}
& N_{f i, c r, z}=\Pi^{2}(E I)_{f i, e f f, z} / \ell_{\theta}^{2} \text { with } \ell_{\theta}=0.5 \ell_{0}= \\
& 1875 \mathrm{~mm} \text { (for fire situation) } \\
& =\pi^{2} \times 17.12 \times 10^{12} / 1875^{2}=48013185 \mathrm{~N} \\
& \text { The } \quad \text { reduced } \quad \text { slenderness }
\end{aligned}
$$$$
\text { ratio: }
$$$$
\bar{\lambda}_{\theta}=\sqrt{N_{\text {fi.pl.R }} / N_{\text {fi.cr.z } z}} \text { where } N_{\text {fi.pl.R }} \text { represents }
$$
the value of $N_{f i . p l . R d}$ when all the safety coefficients are taken as equal to unity. The concrete contribution was previously evaluated with $\lambda_{M, f i, c}=1.30$, hence it is consequently adapted. The other contributions have all been calculated with a safety coefficient equal to unity. It follows therefore:

$N_{f i, l, R}=711494.9+909846.0+1884000.0+2693511.1 \times 1.30$

$=7006905.3 \mathrm{~N}$ and $\bar{\lambda}_{\theta}=\sqrt{\frac{7006905.3}{48013185}}=0.382$

$\rightarrow \chi_{0}=0.9066$. The coefficient representing the slenderness of the column around axis $\mathrm{z}$ is obtained in the same manner from the buckling curve $c$ [7] or from the equation (4). The buckling resistance when the column is concentrically loaded is: $\quad N_{f_{i}, R d}=\chi_{0} N_{f_{i}, p l, R d}=$ $0.9066 \times 6198852.0=5619879.2 \mathrm{~N}$ or $5619.9 \mathrm{kN}$. The reduction coefficient buckling with the eccentricity e $=98$ $\mathrm{mm}$ is from equation (7) in case of fire for 60 minutes:

$$
\begin{aligned}
& \chi_{e}=\frac{\chi_{0}\left(\bar{\lambda}_{\theta}\right)}{1+\frac{4 . e}{b\left(\frac{1}{\chi_{0}\left(\bar{\lambda}_{\theta}\right)}-0.3 \bar{\lambda}_{\theta}^{2}\right)}} \\
& =\frac{0.9066}{1+\frac{4 \times 98}{391 \times\left(\frac{1}{0.9066}-0.3 \times 0.382^{2}\right)}}=0.4668
\end{aligned}
$$

It follows therefore that the buckling resistance of the column eccentrically loaded with reduced $\mathrm{e}=98 \mathrm{~mm}$ is: $N_{f i, R d, e}=\chi_{e} \cdot N_{f i, R d}=0.4658 \times 5619879.2=$ 2.617532 .3 or $2617.5 \mathrm{kN} \geq \mathrm{N}_{\mathrm{sd}, \mathrm{fi}}=2110 \mathrm{kN}$. The calculation by EC4 method gives a value of $2992 \mathrm{kN}$ (= $\left.N_{f i, R d, e}=r_{e} \cdot N_{f i, R d}=5619.9 \times 0.5323\right)$, which is representing an error of $15 \%$ ). It is clear that the column satisfies the requirements for a fire resistance of 60 minutes (R60). In general, the fire design becomes the most critical if a column is to achieve a fire resistance in excess of 60 minutes $[11,12]$.

\section{Parametric analysis}

The fire resistance of a column depends on many parameters such as the applied load, the amount of concrete cover, the slenderness ratio, the steel grade, the concrete strength, the amount of reinforcement, and so on...). Its optimisation, therefore, requires several successive calculations. For this reason, the previously described method was codified in a computer program to investigate the effect of load level, slenderness ratio, concrete cover, and the amount of eccentricity on the fire resistance.

\subsection{Effect of load level}

To examine the influence of load level on the previously described column, the load ratio, $\eta=N_{a p p} / N_{d}$ 
(where $N_{a p p}$ represents the applied load, and $\mathrm{N}_{\mathrm{d}}=$ $6022.9 \mathrm{kN}$ the load capacity of the column at ambient temperature $\mathrm{t}=0 \mathrm{~min}$ ) is varied between 0 and 1 . The results are shown on Fig.7 for an eccentricity e $=98 \mathrm{~mm}$, concrete cover $\mathrm{e}=60 \mathrm{~mm}$ and slenderness ratio $\lambda=33.22$ which is corresponding to the column height $\ell_{0}=3750 \mathrm{~mm}$. For a load level of $0.50 \%$, corresponding to $3011.5 \mathrm{kN}$, the column has a fire resistance of about $49.32 \mathrm{~min}$, which is less than R60 as obtained previously. For $\eta \geq 0.8$, the fire resistance of the column is considered as inexistent.

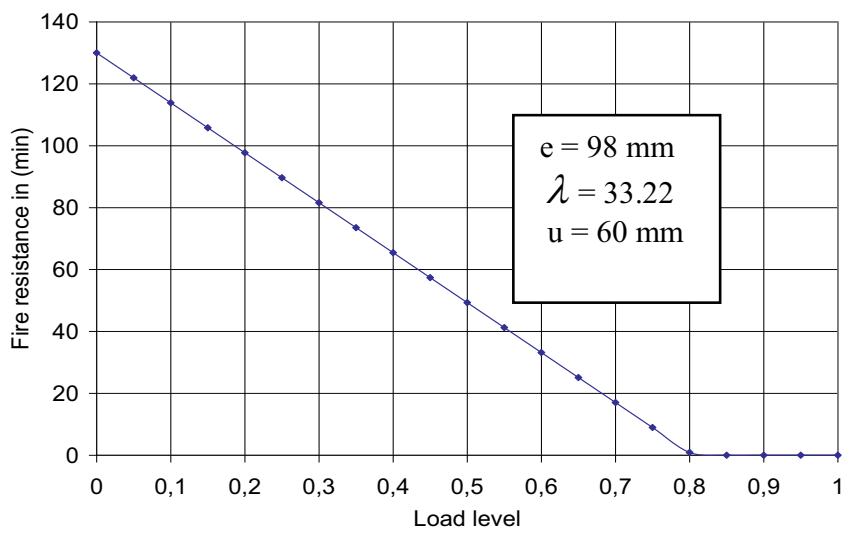

Fig. 7: Effect of load level on fire resistance

\subsection{Effect of slenderness ratio}

To examine the effect of the slenderness ration on the fire resistance of the column, different ratios ranging from a value of $\lambda=8.86$ (i.e. $\ell_{0}=1 \mathrm{~m}$ ), for very short columns to $\lambda=79.73$ (i.e. $\ell_{0}=9 \mathrm{~m}$ ) for very elongated columns. The value of the axial load $\mathrm{P}$ is considered constant and taken equal to $2110 \mathrm{kN}$, which is the normal design load in a fire. The results obtained for $\mathrm{e}=98 \mathrm{~mm}, \mathrm{u}=60 \mathrm{~mm}$ are shown in figure 8 where it can be noticed that there is a quasi-linear decrease of the fire resistance with increasing slenderness. For comparison, this column was found to have a fire resistance of $78.14 \mathrm{~min}$ for a slenderness value equal to 24.36 .

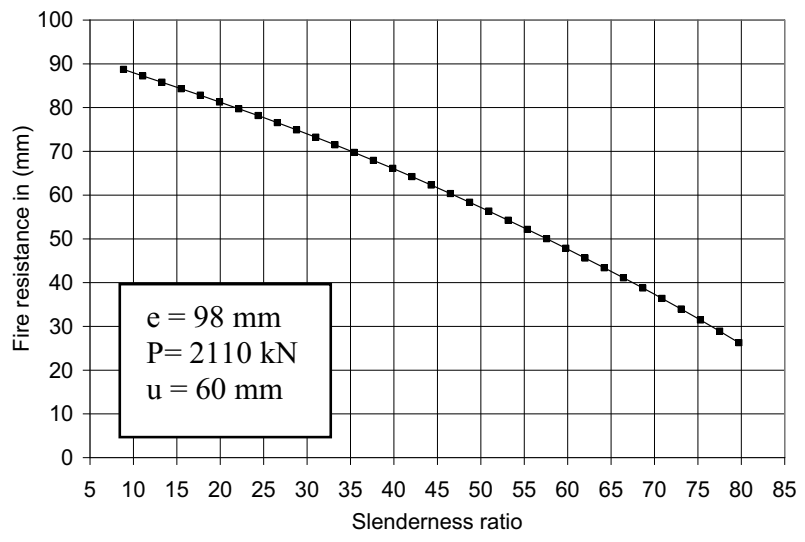

\subsection{Effect of concrete cover}

Figure 9 shows the effect of concrete cover $u=\sqrt{u_{1} \times u_{2}}$ on the fire resistance of the column subject to a constant axial compressive load of $\mathrm{P}=2110$ $\mathrm{kN}$. The results corroborate the range of optimal values recommended in EC4. Beyond a value of $60 \mathrm{~mm}$, the fire resistance starts to drop.

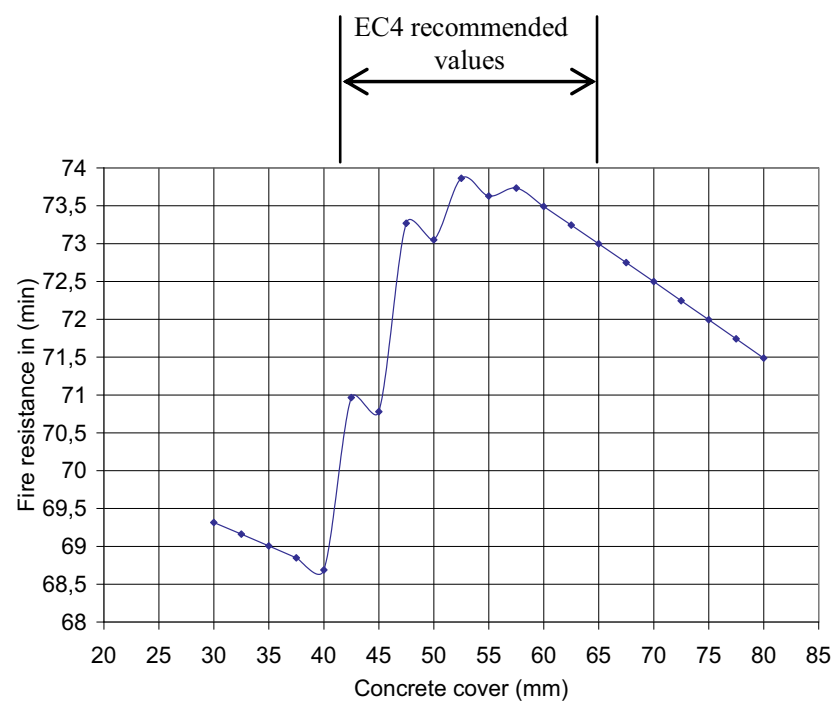

Fig. 9: Effect of concrete cover on fire resistance

\subsection{Effect of eccentricity}

Fig. 10 shows the effect of loading eccentricity on the fire resistance varying from a value of $\mathrm{e}=0 \mathrm{~mm}$, for centered column to $\mathrm{e}=195.5 \mathrm{~mm}$ equal to the half of the wide of the cross-section of the column which is representing the highest limit of the proposed procedure. The value of the axial load $\mathrm{P}$ is considered equal to 2110 $\mathrm{kN}$ and also for the concrete cover and slenderness taken constant equal respectively to $\mathrm{u}=60 \mathrm{~mm}$ and $\lambda=33.32$ which is corresponding to a length colomn of $\ell_{0}=3.75 \mathrm{~m}$. It can be noticed that beyond $30 \mathrm{~mm}$ there

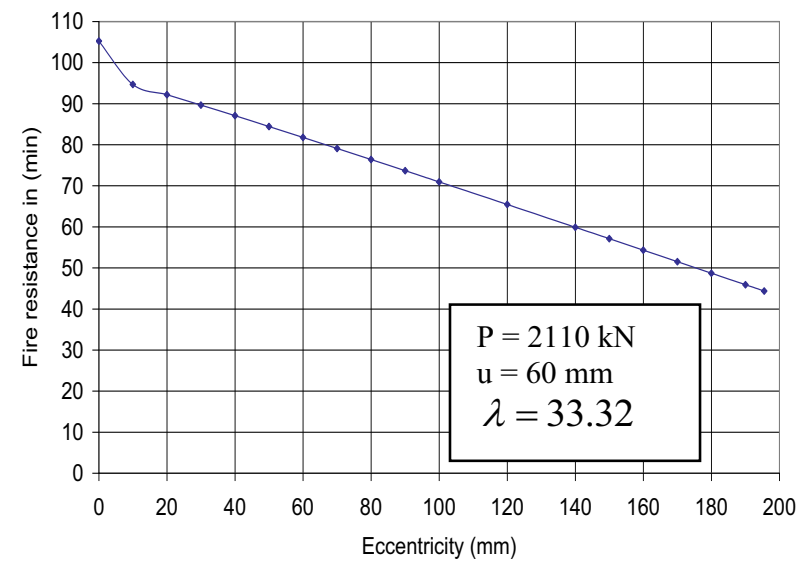

Fig.10: effect of eccentricity on fire resistance

Fig. 8: Effect of slenderness on fire resistance 
is a quasi-linear decrease of the fire resistance with increasing eccentricity. For comparison, this column was found to have a fire resistance of $105.25 \mathrm{~min}$ for a centrically loaded column $\mathrm{e}=0 \mathrm{~mm}$.

\section{Conclusions}

The design for resistance of a partially encased composite steel-concrete column was succinctly described using the simplified method in Appendix G of EC4 1-2. A practical method based on Campus-Massonet criteria which is developed initially to steel structures with combined compression and bending is adapted for the calculation of the buckling resistance of eccentrically loaded columns. The latter at room temperature or in fire situation is expressed by a simple formula as a function of an equivalent buckling coefficient taking into account the amount the eccentricity of the compressive applied load. The method proposed combines accuracy, efficiency and convenience obviating the need of $\mathrm{M}-\mathrm{N}$ interaction diagrams and long iteration process as EC4 procedure. Otherwise, the estimation of the fire resistance for a given loading is made on the assumption based on the linearity with the level applied compressive load.

The chosen worked example shows that the design for fire becomes critical for classes of fire resistance above R60. The procedure was codified in a program, which was subsequently used to investigate the effects of load level, slenderness ratio, and reinforcement cover on the fire resistance of the column. It was found that the fire resistance of a column subjected to an eccentric load decreases gradually with the increase in the load level, the slenderness ratio or the amount of the eccentricity. For a fire resistance of one hour, time enough to evacuate the building of all its occupants, it recommended to use $\eta \leq 0.5$ and $\lambda \leq 45$. The range of values of reinforcement cover suggested by EC4 leads to a better fire resistance except for $\mathrm{u}=60 \mathrm{~mm}$ where there is a decline of the about $10 \%$.

\section{References}

1. Eurocode 4: Design of composite steel and concrete structures- Part 1-2, general rules Structural fire design, BS EN 1994-1-2, 2005.

2. O. Jungbluth, Optimierte Verbandbauteile, Stahlbau Handbuch 1, Stahlbeau-Verglas-Gmbh, Köeln, (1982).

3. JM] Franssen , V. Kodur, R. Zaharia, Design Steel Structures for fire safety, CRC Press, (2009).

4. A. Bruls, P. Vandevelde, Sécurité contre l'incendie dans les bâtiments- Partie 1 prévention passive. Universités de Liège et de Gent, 2000.

5. JC Dotreppe, Calcul et conception des structures soumises à l'incendie- Notes complémentaires. Université de Liège, Faculté des sciences appliquées, (2000).
6. ISO Standard 834: Fire resistance testsElements of building construction, International organisation for Standardization, Geneva, 2002.

7. Eurocode 3: Design of steel structures- Part 1-1: general rules and rules for buildings . BS EN 1993-1-1: 2005.

8. R. Maquoi, Eléments de constructions métalliques- Notes cours, Département MSM, Université de Liège, Belgique, 1988.

9. Eurocode 3: Design of steel structures- Part 1-2: general rules- Structural fire design. BS EN 1993-1-1: 2005.

10. Eurocode 1: Actions sur les structures, Partie 1.2 : actions générales- actions sur les structures exposées au feu, Comité Européen de Standardisation, 2003.

11. J. Mathieu, Application de l'EC4, poteau mixte partiellement enrobé sous charge axiale centrée. Revue Construction Métallique, EC4-MIX 1-01, N01, (2001).

12. ARBED Recherches, Luxembourg. Outils pratiques de dimensionnement pour éléments mixtes acier-béton soumis à l'incendie, compte tenu de l'interaction entre l'effort normal et le moment de flexion, Recherche CCE, 7210 SA/504, 1985-87, Rapport technique RT1, mars 1986. 